\title{
The Cultural Differences in Etiquette and Customs Between China and Britain in Nonverbal Communication
}

\author{
Huan Yang \\ Hubei University of Arts and Science, Xiangyang, Hubei, China
}

\begin{abstract}
Nonverbal behavior as well as verbal behavior, is closely related to culture when expressing ideas. Due to the huge differences between Chinese and English culture, there are also a lot of differences in nonverbal communication. By comparing the common etiquette and customs in nonverbal communication activities between China and Britain, meanwhile the cultural differences between them are figured out.
\end{abstract}

Key words: nonverbal communication; social etiquette; cultural differences

Interpersonal communication is carried out through two forms, one is verbal behavior, and the other is nonverbal behavior. Nonverbal communication involves all those nonverbal stimuli in a communication setting that are generated by both the source and his or her use of the environment and that have potential message value for the source or receiver. The form of nonverbal behavior is conventional, thus varying from culture to culture. In other words, nonverbal behaviors, like verbal behaviors, are connected with culture while expressing our opinions. The huge difference between China and Britain is not only reflected in verbal communication, but also in non-verbal communication, even in every gesture. The differences often easily come with cultural misunderstandings and communication barriers. This paper takes the non-verbal communication etiquette norms often encountered in Chinese and Western communication as an example to compare the cultural differences between Chinese and Western cultures.

\section{Greeting}

The mutual simplest form of non-verbal greetings between China and Britain is nodding, smiling, waving, etc. However, the gestures of greetings between the two cultures vary. For Chinese, we usually raise the right arm, swing the palm toward the other party a few times or just raise it for an instant, which is sometimes difficult to distinguish from the farewell. In English-speaking countries, they express "hello" or "goodbye" through lifting the palm outward and move it downward. Their actions seem a bit funny to us. Whereas our gesture of "hello" is often mistaken for "goodbye" by them. The Chinese nod when smiling at each other and raise our hands at the same time. However, British sometimes raise their eyebrows and nod their heads at the same time, while Australians squeeze their eyes. To the Chinese, they seem to be making funny faces. English-speaking men often take off their hats or touch their hats when they come across their friends on the way or show gratitude to women. If they want to shake hands, it is polite to take off hats, too. It is the etiquette that is left by medieval swordsmen. In English-speaking countries, friends of the opposite sex or good female friends meeting 
again after a long time will hug or kiss their cheeks; in China, friends of the same or opposite sex meeting again after a long time will shake hands or hug enthusiastically. We will not kiss each other except our lover.

Chinese teachers often complain that foreign students from English-speaking countries, especially those from the UK, often pass by teachers without greetings as if there is no one. Some British students said, "It's nothing to greet, isn't it crazy?" This view of British students is not necessarily widely representative in English-speaking countries. Australians hold the idea that greeting is an act of politeness. However, there is often a difference between China and Britain who greets first.

Chinese culture requires that between the subordinate and the superior and the student and the teacher, the former should actively greet to show respect. English culture is quite different.

The elders, superiors, and teachers are apt to take the initiative, because the superiors and teachers may be thinking about problems and don't like being disturbed. In the UK, it's likely for them to talk about the weather like, lovely weather, isn't it? In China, people always ask "have you eaten yet?" when they meet on the way. The former may be due to the fickle weather in the UK, with so many cloudy and rainy days, so people are more concerned about the weather. In China, the issue of eating has not been a particular concern for people for a long time, so it has become a topic of frequent discussion.

\section{Visit}

In English speaking countries, visitors usually make an appointment in advance. In China, it is generally necessary to do so when doing business. Personal visits are often made without prior appointment, especially between friends and colleagues. Likewise, it is not necessary to make an appointment for a courtesy call, wedding or funeral event, or visiting patients after a friend's return from a long journey. It is precisely because of this difference that in the communication between China and the west, sometimes some visits by Chinese people will result in what is opposite to our assumption. In English speaking countries, the invitation comes generally early. For example, when inviting people to have dinner or participate in a party, they should inform each other at least one week in advance, and they should also send out the invitation in the name of the couple, or even the hostess. The response to it is also earlier. Chinese invite people and make an appointment later than that, and reply to it later, too. In English speaking countries, when invited to dinner, it is polite for guests to arrive on time or a few minutes late, while arriving early is not only impolite, but also disrupting unprepared hostess. On the contrary, in China, it is polite for people to arrive on time or a few minutes in advance.

The above differences are due to the fact that out of consideration for others, Chinese people think it's a bit impolite to let the host wait. While people in English speaking countries emphasize that individuals are not restrained. Of course, a practical reason is that in the west, the hostess ought to be given enough time to prepare (such as dressing up). In China, people like to eat hot dishes, and the late arrival of guests will add a lot of trouble to the hostess.

\section{The Principle of Ladies First}

"Ladies first" means that men have to give women priority in various occasions. Since the Women's Liberation Movement, some young people have believed that if the principle is used, young women will regard it as an insult. However, it is still a widely followed principle to give priority to women in the interaction of the West and the international community. In cross-cultural communication, it's a disrespect to ignore this principle. When introducing women in social occasions, the traditional order in English-speaking countries is finicky. Although nowadays, people are less and less concerned about the order of introductions, they still cannot completely ignore the requirement of respecting ladies in formal occasions or among persons with high social status. The only exception is the British prince. When a man and a woman meet for the first time, it is up to the woman to decide whether to shake hands, and the woman takes the 
initiative. When introducing guests indoors, men except the elderly are supposed to stand up as well as the hostess. However, other ladies stand up only when they are introduced to the host or men much older than them.

The Chinese do not have the custom of "ladies first" and are not accustomed to many protocols in English-speaking countries. In China, women are not given priority, but our behaviors are supposed to base on two principles: first, those in need of care are given priority, including the elderly, the weak, the sick, the disabled, the pregnant, and youngsters; secondly, respected people are given priority, such as superiors, elders, VIPs, heroes, etc. are preferred. However, we must obey international conventions and obey the etiquette of ladies first when dealing with diplomatic affairs.

\section{Privacy}

For most British and Americans, it is considered impolite to ask about age, income, marital status, and religious beliefs when they meet for the first time such as "How old are you?", "How much do you make?" or "Are you married?". Since Confucian culture has a profound and far-reaching influence on Chinese people, we have a tradition of "courtesy demands reciprocity". Therefore, in addition to phatic expressions, Chinese people should also inquire about family conditions and personal circumstances to show concern and frankness.

\section{Praise}

The most common gesture used by Chinese people to speak highly of people is to thumb up, while the most commonly used gesture in English-speaking countries is the gesture of OK. For them, thumbs-up generally also means "good", and you can even rise both thumbs up to express appreciation. However, the thumb-up gesture is more intricate in English-speaking countries. It can also express gratitude, bravery, blessing, encouragement, conceit, superiority and so on. When being praised, people from English-speaking countries smile happily, accept the compliments and say "thank you" loudly. However, the Chinese expressed their embarrassment and sense of shame, and declined.

\section{Requirements and Criticism}

People from English-speaking countries make requests face to face and do not want others to interfere with. If the Chinese want to put forward an unsure request, they sometimes like to mediate through a third party who is familiar with or understands both sides. If we want to refuse someone's request, we are also apt to tell it through a third party. Likewise, to criticize someone, a third party is also there to help. People in English-speaking countries are disgusted with such practice. It is believed that the interference of a third party with the matter between two persons is an attack of personal private affairs; it is a lack of confidence and distrust of the other party to put forward requirements for others indirectly. More serious discussion will be made to figure out how to analyze and understand this practice.

But a few points are certain. First, this phenomenon is common in Chinese communication. Second, this practice has its profound cultural and psychological effects, which is to take care of the face of others, afraid of screwing up the relations with others. Therefore, we should make full use of the characteristics of mutual care in Chinese collective culture and find a person who is familiar or trusted by both parties to play a role in it, so that the problem can be properly worked out. People in English-speaking countries who take the individual as the center and strictly maintain their independent selfesteem are of course incompatible with this practice. Third, I am afraid that this phenomenon cannot be understood and dealt with as easily as the cultural inferiority such as spitting.

\section{Ending}

In communication, the amount of information provided by a person's manner and behavior takes greatly over that by his conversation. Moreover, there are a large number of paralinguistic signals of nonverbal behavior in conversation, such as non-semantic sounds, pauses, silence, laughter, and turn-taking in conversation. Of course, there is to be a comprehensive and correct understanding of the role of nonverbal behavior in communication and its relationship with 
verbal one. On the one hand, we can see that in communication, isolated language behaviors that are separated from nonverbal cooperation are often difficult to achieve effective communication purposes; on the other hand, we must also recognize that nonverbal behaviors can only be expressed clearly in a particular context. And a nonverbal behavior can only provide clear information when combined with a verbal behavior or other non-verbal behavior.

Therefore, it does not work to understand or study the meaning of certain non-verbal behavior in isolation from verbal behavior or other non-verbal behavior. To study non-verbal communication in cross-cultural activities is of great significance to truly master and understand various differences in cross-cultural communication, improve the level of foreign language teaching, make students learn more about the differences between Chinese and Western cultures and avoid cultural shock and conflicts that may be caused by non-verbal communication.

\section{Conflicts of Interest}

The author declares no conflicts of interest regarding the publication of this paper.

\section{References}

[1] He Z.H. (2019). Analysis of Family Education Differences between China and America under Cross-Cultural Perspective. Overseas English, (17):263-264+266.

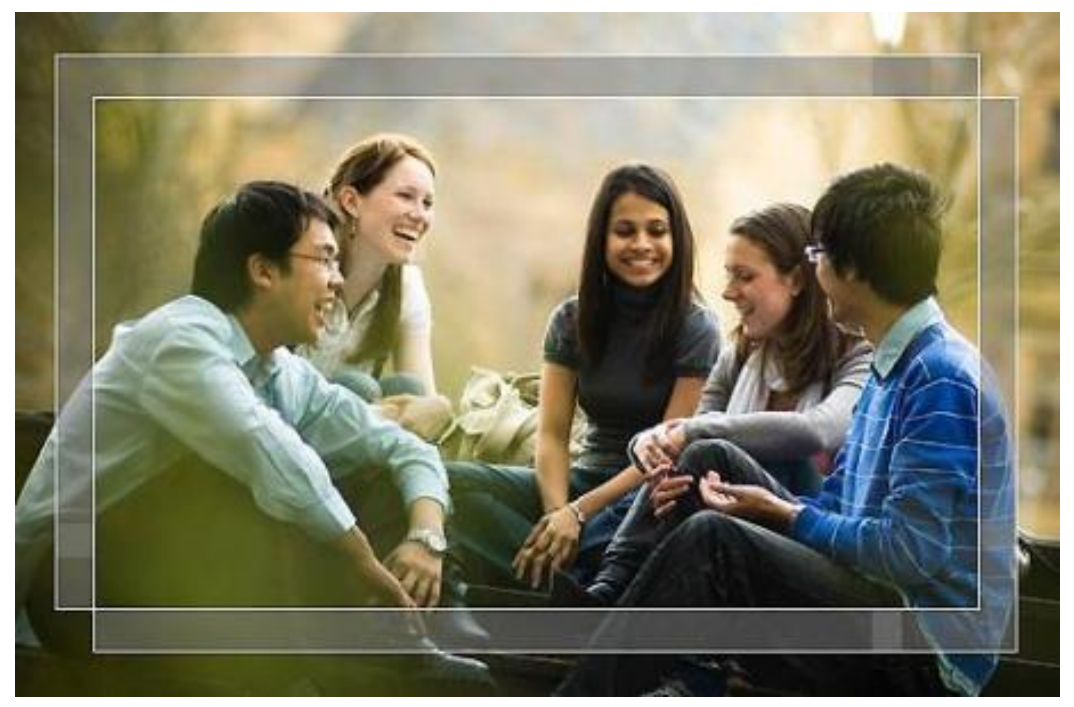

